\section{BRAZIULIAN JOURNAL}

OF MEDICAL AND BIOLOGICAL RESHARCH

www.bjournal.com.br
ISSN 0100-879X

Volume 43 (02) 124-225 February 2010

BIOMEDICAL SCIENCES

AND

CLINICAL INVESTIGATION

Braz J Med Biol Res, February 2010, Volume 43(2) 127-133

Genetic variability of vascular endothelial growth factor and prognosis of head and neck cancer in a Brazilian population

M.T. Ruiz, P.M. Biselli, J.V. Maniglia, E.C. Pavarino-Bertelli and E.M. Goloni-Bertollo

The Brazilian Journal of Medical and Biological Research is partially financed by
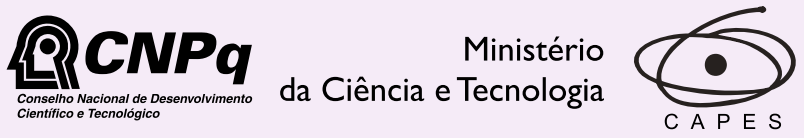

Ministério da Educação

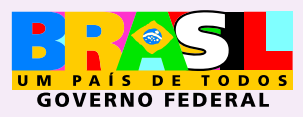

Institutional Sponsors 


\title{
Genetic variability of vascular endothelial growth factor and prognosis of head and neck cancer in a Brazilian population
}

\author{
M.T. Ruiz' ${ }^{1}$, P.M. Biselli ${ }^{1}$, J.V. Maniglia ${ }^{2}$, E.C. Pavarino-Bertelli ${ }^{1}$ \\ and E.M. Goloni-Bertollo ${ }^{1}$ \\ ${ }^{1}$ Unidade de Pesquisa em Genética e Biologia Molecular, Departamento de Biologia Molecular, \\ 2Departamento de Otorrinolaringologia e Cirurgia de Cabeça e Pescoço, \\ Faculdade de Medicina de São José do Rio Preto, São José do Rio Preto, SP, Brasil
}

\begin{abstract}
Vascular endothelial growth factor (VEGF) is one of the most potent endothelial cell mitogens and plays a critical role in angiogenesis. Polymorphisms in this gene have been evaluated in patients with several types of cancer. The objectives of this study were to determine if there was an association of the $-1154 \mathrm{G} / \mathrm{A}$ polymorphism of the VEGF gene with head and neck cancer and the interaction of this polymorphism with lifestyle and demographic factors. Additionally, the distribution of the VEGF genotype was investigated with respect to the clinicopathological features of head and neck cancer patients. The study included 100 patients with histopathological diagnosis of head and neck squamous cell carcinoma. Patients with treated tumors were excluded. A total of 176 individuals 40 years or older were included in the control group and individuals with a family history of neoplasias were excluded. Analysis was performed after extraction of genomic DNA using the real-time PCR technique. No statistically significant differences between allelic and genotype frequencies of -1154G/A VEGF polymorphism were identified between healthy individuals and patients. The real-time PCR analyses showed a G allele frequency of 0.72 and 0.74 for patients and the control group, respectively. The A allele showed a frequency of 0.28 for head and neck cancer patients and 0.26 for the control group. However, analysis of the clinicopathological features showed a decreased frequency of the A allele polymorphism in patients with advanced ( $\mathrm{T} 3$ and $\mathrm{T} 4)$ tumors $(\mathrm{OR}=0.36 ; 95 \% \mathrm{Cl}=0.14-0.93 ; \mathrm{P}=0.0345)$. The $-1154 \mathrm{~A}$ allele of the VEGF gene may decrease the risk of tumor growth and be a possible biomarker for head and neck cancer. This polymorphism is associated with increased VEGF production and may have a prognostic importance.
\end{abstract}

Key words: Head and neck cancer; Polymorphism; Genetic; VEGF gene

\section{Introduction}

Head and neck squamous cell carcinoma is a significant cause of morbidity and mortality with 481,100 new cases reported annually worldwide. Two-thirds occur in developing countries, with an overall 5-year mortality rate of approximately $50 \%(1,2)$. In São Paulo State, Brazil, the occurrence of 4,510 new cases was estimated for 2008 (3).

The growth of solid tumors depends on angiogenesis, the process by which new blood vessels develop from the endothelium of the preexisting vasculature. Tumors promote angiogenesis by secreting or activating angiogenic factors that stimulate endothelial migration, proliferation, and capillary morphogenesis. Newly formed blood vessels supply the tumor with nutrients and oxygen, dispose of the metabolic waste products of tumor cells, generate paracrine stimuli, and provide potential routes for tumor dissemination. Thus, tumor-induced angiogenesis plays a pivotal role in cancer progression and metastasis $(4,5)$.

Vascular endothelial growth factor (VEGF) is one of the most potent endothelial cell mitogens and plays a critical role in angiogenesis. VEGF binds specifically to two transmembrane VEGF receptor tyrosine kinases on endothelial cells to initiate intracellular signal transduction pathways that mediate angiogenesis and vascular permeability (6). The properties of angiogenesis correlate with tumor aggressiveness, with intratumor microvessel density and they have been identified as an independent prognostic factor (7).

Correspondence: E.M. Goloni-Bertollo, Unidade de Pesquisa em Genética e Biologia Molecular, Departamento de Biologia Molecular, Faculdade de Medicina de São José do Rio Preto, Av. Brigadeiro Faria Lima, 5416, 15090-000 São José do Rio Preto, SP, Brasil. Fax: +55-17-3201-5841. E-mail: eny.goloni@famerp.br

Received April 14, 2009. Accepted December 16, 2009. Available online January 15, 2010. Published February 1, 2010. 
VEGF forms the new blood vessels of the tumor by acting as an endothelial cell mitogen, thereby it promotes the growth and invasion of the tumor. VEGF functions to increase vascular permeability, which causes edema in the extracellular matrix and supports the spouting and splitting of new blood vessels by making fibrin freely available. VEGF also allows the intravascular circulating tumor cells to easily penetrate the basement membrane of blood vessels (8).

Several lines of compelling evidence from in vitro and in vivo experiments have shown that increased VEGF expression is associated with tumor growth and metastasis, whereas the inhibition of VEGF signaling results in suppression of both tumor-induced angiogenesis and tumor growth (6).

The VEGF gene is located on chromosome 6p21.3 and consists of 8 exons. At least 30 single-nucleotide polymorphisms have been described in this gene. Among these, there is evidence that the $-634 \mathrm{G} / \mathrm{C},-1154 \mathrm{G} / \mathrm{A}$, and $-2578 \mathrm{C} / \mathrm{A}$ VEGF polymorphisms have been shown to be associated with increased VEGF production (9-11).

VEGF polymorphisms have been evaluated in patients with skin $(12)$, bladder $(13)$, lung $(14,15)$, prostate $(16,17)$, stomach $(18)$, and breast $(19,20)$ cancers. Several studies have focused on the potential prognostic importance of VEGF polymorphisms $(13,19,20)$. The -1154GG VEGF genotype is associated with higher VEGF production and is located in the promoter region of the gene (11). The -1154A/A genotype has been shown to be associated with a decreased risk for prostate cancer and less advanced melanoma (14-16).

Six studies have investigated VEGF polymorphisms in head and neck cancers. In one study, an association of $-460 \mathrm{C} / \mathrm{T}$ polymorphism was reported in oral cancer. The distribution of the -460TT homozygote in the patient group was greater than that in the control group and the results showed that with a high $-460 \mathrm{TC}$ ratio there is a higher risk for oral cancer in the patients (21).

A second study showed an association between +960C/T VEGF polymorphism and oral cancer (22). This study clearly indicates that the low production of VEGF by the $\mathrm{T}$ allele is associated with increased risk for oral cancer. Cheng et al. (24) also identified an association between $+960 \mathrm{C} / \mathrm{T}$ polymorphism and vascular invasion in oral squamous cell carcinoma, whereas recently Vairaktaris et al. (23) were not able to demonstrate an association between this polymorphism and the disease in the logistic regression models. However, the genotype VEGF -460CT was associated with early stage tumors.

One study that analyzed the polymorphism VEGF $-2578 \mathrm{C} / \mathrm{A}$ has suggested that carriers of VEGF $-2578 \mathrm{C}$ allele may play a role in susceptibility to nasopharyngeal carcinoma (25).

In the $-1154 \mathrm{G} / \mathrm{A}$ polymorphism of the VEGF gene, the -1154G/G genotype of the VEGF gene appears to increase the risk for laryngeal squamous cell carcinoma (26). The polymorphism -1154G/A VEGF has been shown to be associated with differential expression of VEGF in vitro and has been implicated in the risk for several types of tumors and other diseases with putative angiogenic components. However, some of the data are contradictory. It is possible that functional variations of the VEGF gene may contribute to the progression of head and neck cancer. To test this hypothesis, the aims of the present study were to investigate the association of the $-1154 \mathrm{G} / \mathrm{A}$ polymorphism of the VEGF gene with head and neck cancer and to determine whether the interaction of this polymorphism with lifestyle and demographic factors may be associated with a higher risk. In addition, the VEGF genotype distribution was investigated in relation to the clinicopathological features of head and neck cancer patients.

\section{Material and Methods}

A prospective study of 91 male and 9 female patients diagnosed with head and neck cancer (average age: 57 years; range: 36-80 years) was conducted at Hospital de Base, São José do Rio Preto, São Paulo, Brazil. Diagnosis was made from pathological specimens obtained during total excision surgery or biopsy. All tumor cells were squamous cell carcinomas and the samples were collected before the beginning of treatment. The primary anatomic sites included the oral cavity $(N=34)$, oropharynx $(N=24)$, hypopharynx $(\mathrm{N}=8)$, supraglottis $(\mathrm{N}=11)$, and glottis $(\mathrm{N}$ $=18$ ). The primary site of the tumor was unknown for 5 of the 100 patients.

A control group contained 176 blood donors with no familial history of cancer for three generations.

Alcoholism was defined as the intake of alcohol at a frequency determined without a quantitative analysis and individuals who had an average of four drinks a week were considered to be alcohol consumers. The smoking habit was defined as the consumption of at least 5 cigarettes/day.

The patients were staged according to the tumor-nodemetastasis (TNM) classification of the International Union against Cancer (27).

The study protocol was approved by the Ethics Committee of the Medical School of São José do Rio Preto, São Paulo (FAMERP) and all participants gave written informed consent to participate in the study.

\section{DNA isolation and genotyping assay}

DNA was isolated from peripheral blood leukocytes by the method of Miller et al. (28). DNA concentration was measured using a Cary spectrophotometer (Varian, USA). Allelic discrimination of the -1154 VEGF polymorphism was achieved with the ABI PRISM 7500 Sequence Detection System (Applied Biosystems, USA) using the fluorogenic 5' nuclease assay with Taqman Minor Groove Binder (MGB) probes. The wild-type Taqman MGB probes were FAM (allele $\mathrm{G}$ ) labeled and the mutants were VIC (allele A) labeled. 
The final volume of each reaction was $5 \mu \mathrm{L}$, consisting of $1.5 \mu \mathrm{L}$ Taqman Universal PCR Master Mix (Applied Biosystems), $0.9 \mu \mathrm{M}$ of each primer, $0.2 \mu \mathrm{M}$ of each Taqman probe, and 5 ng genomic DNA. PCR sequencing involved an initial denaturation step at $95^{\circ} \mathrm{C}$ for $10 \mathrm{~min}$ followed by 40 cycles at $92^{\circ} \mathrm{C}$ for $15 \mathrm{~s}$ and $60^{\circ} \mathrm{C}$ for $1 \mathrm{~min}$. Fluorescent signals were measured at $60^{\circ} \mathrm{C}$. The primers and probes for the G-1154A were purchased from Applied Biosystems (ID - C_1647379-10).

The SDS computer program version 2.0 was used to analyze the fluorescence emitted in real-time and at the end of PCR (endpoint read).

\section{Statistical analysis}

Demographic and lifestyle data were analyzed by descriptive statistics and compared by the chi-square test.

The chi-square test and Hardy-Weinberg equilibrium (HWE) were used for statistical analysis of the allele and genotype distributions of this polymorphism. AP value $<0.05$ was used to establish statistical significance. Multiple logistic regression models were used to determine the effect of the variables on head and neck squamous cell carcinoma. The model included age (reference: $<54$ years - mean of the groups), gender (reference: female), smoking habit (reference: non-smokers), and drinking habit (reference: non-drinkers). Data are reported as odds ratio (OR) and $95 \%$ confidence intervals $(95 \% \mathrm{Cl})$.

Clinicopathological features were analyzed by multiple logistic regression. The anatomic primary site of the tumor was divided into three head and neck cancer regions: oral cavity, pharynx and larynx. The clinical staging of head and neck cancer was performed according to the TNM classification of the International Union against Cancer (27). Tumor classification was divided into low $\mathrm{T}(\mathrm{T} 1, \mathrm{~T} 2)$ and high $\mathrm{T}$ $(\mathrm{T} 3, \mathrm{~T} 4)$ categories. $\mathrm{N}$ classification was dichotomized into negative (N0) and positive involvement of lymph nodes (N1, N2, N3). Stage grouping was divided into early stage (Stage I or II) and advanced stage (Stage III or IV) categories. The

Table 1. Distribution of the characteristics of patients and controls.

\begin{tabular}{lcc}
\hline Variable & Patients (N=100) & Controls (N=176) \\
\hline Male & $91(91 \%)$ & $119(68 \%)^{*}$ \\
Female & $9(9 \%)$ & $57(32 \%)^{*}$ \\
Age (years) & $57 \pm 10$ & $52 \pm 12^{*}$ \\
Smoking habit (\%) & $91(91 \%)$ & $99(56 \%)^{*}$ \\
Drinking habit (\%) & $80(80 \%)$ & $61(35 \%)^{*}$ \\
\hline
\end{tabular}

Data are reported as number with percent in parentheses or means \pm SD. The smoking habit was defined as the consumption of at least 5 cigarettes/day. The drinking habit was defined as the consumption of an average of four drinks a week. ${ }^{*} P<0.05$ compared to patients (chi-square test). analysis of $\mathrm{M}$ classification was not performed since all patients were classified as M0.

Disease-free survival was defined as the time from the date of diagnosis to the date of first local or distant recurrence or last contact. Overall survival analysis was defined as the time from the date of diagnosis to death if the patient died from head and neck cancer, or to last contact. Survival curves were plotted using the Kaplan-Meier method and the differences between groups were calculated by the log-rank test.

Statistical analyses were performed using the computer program Minitab for Windows (version 12.22). A value of $P$ $<0.05$ was considered to be statistically significant.

\section{Results}

\section{Demographic data and lifestyle factors}

Table 1 shows the distribution of the variables of patients and controls. There were statistically significant differences between patients and controls for age, gender, and smoking and drinking habits.

\section{VEGF genotype}

The genotype distribution of the polymorphism under study did not deviate from HWE for patients $(P=0.9521)$ or controls $(P=0.0675)$.

The allele and genotype frequencies of the VEGF gene of head and neck cancer patients and of the control group are shown in Table 2. There was no statistically significant difference in the allele distribution of the -1154 VEGF gene G/A polymorphism between controls and head and neck cancer patients. The differences in genotype frequencies between patients and controls were also not significant.

The potential interaction between the distribution of the VEGF genotype and exposure to risk factors for head and neck cancer are shown in Table 3, with no statistical difference being detected using multiple logistic regression.

Table 2. Distribution of the -1154G/A VEGF polymorphism among head and neck cancer patients and controls.

\begin{tabular}{ccc}
\hline & Patients $(\mathrm{N}=100)$ & Controls $(\mathrm{N}=176)$ \\
\hline Genotypes & & \\
GG & $51(51 \%)$ & $100(57 \%)$ \\
GA & $41(41 \%)$ & $59(34 \%)$ \\
AA & $8(8 \%)$ & $17(9.7 \%)$ \\
Alleles & & \\
G & 0.72 & 0.74 \\
A & 0.28 & 0.26 \\
\hline
\end{tabular}

Data are reported as number with percent in parentheses. There were no statistically significant differences between allele distribution or genotype frequencies between patients and controls (chi-square test). 
The associations of the clinicopathological features of head and neck cancer patients with VEGF genotypes are shown in Table 4. Only patients with complete pathological data were considered for this analysis. The analysis showed that the polymorphic $A$ allele was less frequent in patients with T3 and T4 tumors. No significant association of genotype frequency was found for the other clinical parameters. An analysis of metastasis classification was not performed since all patients were classified as M0.

There was no statistical difference between survival curves by genotype. There was also no association be- tween the polymorphism and overall survival (Figure 1A) or evidence for an association between the time of recurrence of the disease and genotype (Figure 1B).

\section{Discussion}

The present study confirms the well-known fact that head and neck cancer development is strongly associated with lifestyle factors, such as alcohol intake and cigarette smoking (29). Furthermore, the significant association between age and gender and this disease was confirmed $(29,30)$.

Table 3. Odds ratio of head and neck cancer related to VEGF genotypes by gender, age, smoking, and drinking habits.

\begin{tabular}{|c|c|c|c|c|}
\hline Characteristic & GG (Patients/Controls) & OR $(95 \% \mathrm{Cl})$ & GA and AA (Patients/Controls) & OR $(95 \% \mathrm{Cl})$ \\
\hline \multicolumn{5}{|l|}{ Gender } \\
\hline Female & $4 / 32$ & 1.00 (ref) & $5 / 25$ & $2.22(0.46-10.55)$ \\
\hline Male & $47 / 68$ & 1.00 (ref) & $44 / 51$ & $1.25(0.64-2.41)$ \\
\hline \multicolumn{5}{|l|}{ Age (years) } \\
\hline$<54$ & $16 / 56$ & 1.00 (ref) & $15 / 42$ & $1.50(0.59-3.82)$ \\
\hline$>54$ & $35 / 44$ & 1.00 (ref) & $34 / 34$ & $1.33(0.61-2.88)$ \\
\hline \multicolumn{5}{|l|}{ Smoking habits } \\
\hline Non-smokers & $5 / 38$ & 1.00 (ref) & $4 / 39$ & $1.08(0.24-4.90)$ \\
\hline Smokers & $46 / 62$ & 1.00 (ref) & $45 / 37$ & $1.40(0.72-2.71)$ \\
\hline \multicolumn{5}{|l|}{ Drinking habits } \\
\hline Use of alcohol & $41 / 38$ & 1.00 (ref) & $39 / 23$ & $1.29(0.61-2.72)$ \\
\hline Non-use of alcohol & $10 / 62$ & 1.00 (ref) & $10 / 53$ & $1.63(0.56-4.71)$ \\
\hline
\end{tabular}

OR data were adjusted for age, gender, smoking, and drinking habits. None of the differences between groups were statistically significant by multiple logistic regression analysis.

Table 4. Clinicopathological features and VEGF polymorphism.

\begin{tabular}{|c|c|c|c|c|}
\hline Variables & GG genotype & OR $(95 \% \mathrm{Cl})$ & GA and AA genotype & OR $(95 \% \mathrm{Cl})$ \\
\hline \multicolumn{5}{|c|}{ Site of tumor $(N=95)$} \\
\hline Oral cavity & 22 & 1.00 (ref) & 20 & $0.81(0.35-1.89)$ \\
\hline Pharynx & 16 & 1.00 (ref) & 11 & $0.73(0.29-1.85)$ \\
\hline Larynx & 14 & 1.00 (ref) & 12 & $0.91(0.36-2.31)$ \\
\hline \multicolumn{5}{|c|}{ Tumor extension $(\mathrm{N}=95)$} \\
\hline $\mathrm{T} 1 / \mathrm{T} 2$ & 11 & 1.00 (ref) & 15 & 1.00 (ref) \\
\hline $\mathrm{T} 3 / \mathrm{T} 4$ & 40 & 1.00 (ref) & $29^{*}$ & $0.36(0.14-0.93)$ \\
\hline \multicolumn{5}{|c|}{ Lymph node involvement $(\mathrm{N}=99)$} \\
\hline No & 26 & 1.00 (ref) & 16 & 1.00 (ref) \\
\hline Yes & 25 & 1.00 (ref) & 32 & $2.20(0.94-5.14)$ \\
\hline \multicolumn{5}{|l|}{ Stage $(N=82)$} \\
\hline $\mathrm{I} / \mathrm{II}$ & 7 & 1.00 (ref) & 9 & 1.00 (ref) \\
\hline $\mathrm{III} / \mathrm{IV}$ & 36 & 1.00 (ref) & 30 & $1.26(0.33-4.71)$ \\
\hline
\end{tabular}

OR data were adjusted for age, gender, smoking, and drinking habits. * $\mathrm{P}<0.05$ compared to $\mathrm{GG}$ (multiple logistic regression analysis). 
In the present study, the allele and genotype distribution of the $-1154 \mathrm{G} / \mathrm{A}$ VEGF polymorphism in patients with head and neck cancer was in close agreement with that reported for healthy Caucasian individuals (31). However, when submitted to univariate and multiple logistic regression analyses, our data showed no significant differences in the allele and genotype distribution for patients with head and neck cancer compared to controls.

Five studies have reported the association of at least one VEGF polymorphisms with head and neck cancer. Ku et al. (21) reported the association between -460T/T VEGF genotype and oral cancer, Yapijakis et al. (22) showed an elevated frequency of heterozygotes with the $+936 \mathrm{C} / \mathrm{T}$ polymorphism and oral cancer, and Cheng et al. (24) identified an association between +960C/C VEGF genotype and vascular invasion in oral squamous cell carcinoma. Nasr et al. (25) reported an association between carriers of VEGF -2578C allele polymorphism and aggressiveness of the tumor in nasopharyngeal carcinoma and Ünal et al. (26) showed an association between the VEGF -1154G/G genotype and larynx cancer.

The VEGF genotype can be divided into low (homozygote AA), intermediate (heterozygote AG) and high expression (homozygote GG). Thus, Unal et al. (26) hypothesized that patients with high expression of the VEGF genotype have more aggressive and metastatic tumor behavior than low expression or heterozygote genotypes.

In lung cancer, the -1154A/A VEGF polymorphism was shown to be significantly associated with less VEGF expression compared to the GG polymorphism, while GA seemed to be related to an intermediate level of expression (14).

In the analysis of clinicopathological features, the decreased frequency of the polymorphic A allele (-1154AA and -1154GA genotypes) in T3 and T4 tumors supports the hypothesis that this allele is associated with decreased angiogenesis. Evidence has shown that the $-1154 \mathrm{G} / \mathrm{A}$ VEGF polymorphism is associated with increases in VEGF production (9-11). The -1154AA genotype is associated with a decreased prostate cancer risk and less advanced melanomas and these data suggest that the polymorphisms involved in the angiogenic pathway may affect the progression or aggressiveness of the tumor $(11,16)$.

Howell et al. (12) reported that the VEGF -1154A/A genotype was associated with the thinner primary vertical growth phase of malignant cutaneous melanomas while VEGF-1154GG was associated with thicker primary tumors. McCarron et al. (16) observed that the VEGF -1154AA genotype is associated with a reduced risk for prostate cancer development. These results indicate that the VEGF genotype may influence tumor growth, possibly via the effects of differential VEGF expressions on tumor angiogenesis. Nasr et al. (25) showed an association between $-2578 \mathrm{C}$ allele carriers and the aggressive forms of nasopharyngeal carcinoma defined by large tumor size and advanced tumor stages.
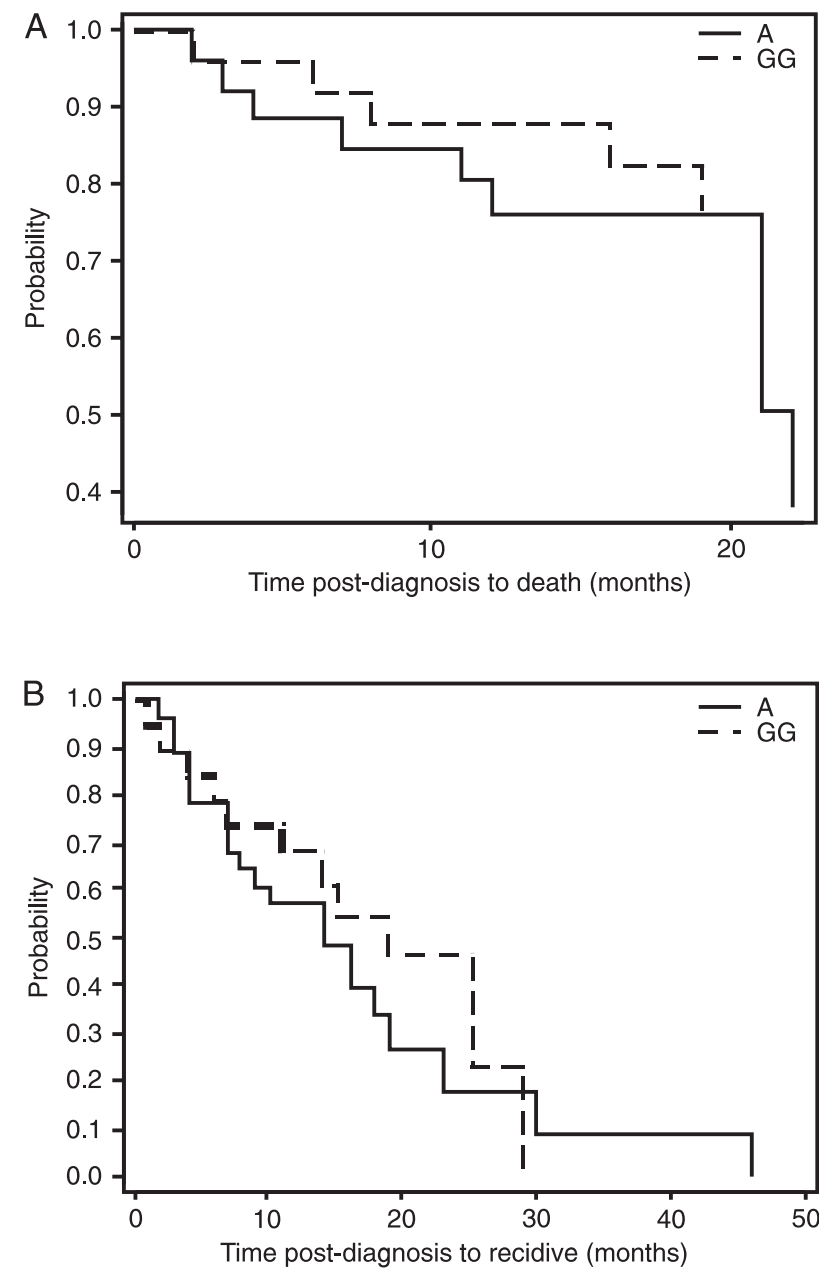

Figure 1. Kaplan-Meier curves for the overall survival $(P=0.1521)$ $(A)$ and relapse time $(P=0.4502)(B)$ for patients according to the -1154G/A VEGF polymorphism.

Several studies have reported that VEGF expression is significantly higher in patients with regional lymph node involvement $(32,33)$ and therefore may promote the progression of oral cancer. In the present study, no association was observed between lymph node involvement and -1154G/A VEGF polymorphism. Moreover, no significant differences between the different tumor stages and the distribution of -1154G/A VEGF polymorphism were observed. In a study of $+936 \mathrm{C} / \mathrm{T}$ VEGF polymorphism, Yapijakis et al. (22) reported an increase in the frequency of the VEGF 936T polymorphic allele, which is associated with lower circulating levels of VEGF.

A clear correlation between the VEGF gene and clinical parameters has not been demonstrated in squamous cell head and neck carcinomas (34). The present study suggests that the VEGF -1154A allele can reduce the risk of tumor growth and thus supports views about the role of 
VEGF in head and neck cancer reported by others. Our result is not surprising because VEGF, as a key mediator of angiogenesis, is more likely to alter the aggressiveness of the tumor than susceptibility to cancer.

The expression of the VEGF gene is also regulated by a variety of hormones, growth factors, and cytokines, including luteotrophic hormone, PDGF, EGF, TGF-b, and IL-6, suggesting that other angiogenic factors may also regulate VEGF expression (31). The process of virtualization is not totally known, but VEGF seems to be the predominant vascular growth factor in most tumors (35). High expression of VEGF is correlated with some solid tumors such as breast cancer (36), colorectal (37), and oral squamous cell carcinoma $(7,38)$. For the last one, positive immunoreactivity of VEGF was associated with a poor prognosis $(7,37)$ and

\section{References}

1. Walker DM, Boey G, McDonald LA. The pathology of oral cancer. Pathology 2003; 35: 376-383.

2. Perez-Ordonez B, Beauchemin M, Jordan RC. Molecular biology of squamous cell carcinoma of the head and neck. J Clin Pathol 2006; 59: 445-453.

3. Instituto Nacional do Câncer. http://www.inca.gov.br.

4. Carmeliet P, Jain RK. Angiogenesis in cancer and other diseases. Nature 2000; 407: 249-257.

5. Poon RT, Fan ST, Wong J. Clinical implications of circulating angiogenic factors in cancer patients. J Clin Oncol 2001; 19: 1207-1225.

6. Ferrara N. VEGF and the quest for tumour angiogenesis factors. Nat Rev Cancer 2002; 2: 795-803.

7. Maeda T, Matsumura S, Hiranuma H, Jikko A, Furukawa S, Ishida T, et al. Expression of vascular endothelial growth factor in human oral squamous cell carcinoma: its association with tumour progression and p53 gene status. J Clin Pathol 1998; 51: 771-775.

8. Lim SC. Expression of c-erbB receptors, MMPs and VEGF in head and neck squamous cell carcinoma. Biomed Pharmacother 2005; 59 (Suppl 2): S366-S369.

9. Mohammadi M, Ollier WE, Hutchinson IV. A functional association study of VEGF gene promoter polymorphisms with VEGF expression by stimulated pbm cells. Hum Immunol 2003; 64: S125.

10. Shahbazi M, Fryer AA, Pravica V, Brogan IJ, Ramsay HM, Hutchinson IV, et al. Vascular endothelial growth factor gene polymorphisms are associated with acute renal allograft rejection. J Am Soc Nephrol 2002; 13: 260-264.

11. Awata T, Inoue K, Kurihara S, Ohkubo T, Watanabe M, Inukai $\mathrm{K}$, et al. A common polymorphism in the 5'-untranslated region of the VEGF gene is associated with diabetic retinopathy in type 2 diabetes. Diabetes 2002; 51: 1635-1639.

12. Howell WM, Bateman AC, Turner SJ, Collins A, Theaker JM. Influence of vascular endothelial growth factor single nucleotide polymorphisms on tumour development in cutaneous malignant melanoma. Genes Immun 2002; 3: 229-232.

13. Kim EJ, Jeong P, Quan C, Kim J, Bae SC, Yoon SJ, et al. Genotypes of TNF-alpha, VEGF, hOGG1, GSTM1, and GSTT1: useful determinants for clinical outcome of bladder reduced survival (7)

The $-1154 \mathrm{~A}$ allele of the VEGF gene decreases the risk of tumor growth and may be an important biomarker in head and neck cancer.

\section{Acknowledgments}

Research supported by FAPESP (\#04/14573-3) and CNPq (\#477665/2004-7, \#305462/2005-9). The authors wish to thank all those participating in this study, FAPESP and CNPq for their support, Prof. Adilia M. Pires Sciarra for her help in writing the text, Prof. Dr. Moacir Fernandes Godoy for his help in the statistical analysis, and FAMERP/ FUNFARME.

cancer. Urology 2005; 65: 70-75.

14. Koukourakis MI, Papazoglou D, Giatromanolaki A, Bougioukas G, Maltezos E, Sivridis E. VEGF gene sequence variation defines VEGF gene expression status and angiogenic activity in non-small cell lung cancer. Lung Cancer 2004; 46: 293-298.

15. Lee SJ, Lee SY, Jeon HS, Park SH, Jang JS, Lee GY, et al. Vascular endothelial growth factor gene polymorphisms and risk of primary lung cancer. Cancer Epidemiol Biomarkers Prev 2005; 14: 571-575.

16. McCarron SL, Edwards S, Evans PR, Gibbs R, Dearnaley DP, Dowe A, et al. Influence of cytokine gene polymorphisms on the development of prostate cancer. Cancer Res 2002; 62: 3369-3372.

17. Sfar S, Hassen E, Saad H, Mosbah F, Chouchane L. Association of VEGF genetic polymorphisms with prostate carcinoma risk and clinical outcome. Cytokine 2006; 35: 21-28.

18. Kim JG, Sohn SK, Chae YS, Cho YY, Bae HI, Yan G, et al. Vascular endothelial growth factor gene polymorphisms associated with prognosis for patients with gastric cancer. Ann Oncol 2007; 18: 1030-1036.

19. Lu H, Shu XO, Cui Y, Kataoka N, Wen W, Cai Q, et al. Association of genetic polymorphisms in the VEGF gene with breast cancer survival. Cancer Res 2005; 65: 5015-5019.

20. Jin Q, Hemminki K, Enquist K, Lenner P, Grzybowska E, Klaes $R$, et al. Vascular endothelial growth factor polymorphisms in relation to breast cancer development and prognosis. Clin Cancer Res 2005; 11: 3647-3653.

21. Ku KT, Wan L, Peng HC, Tsai MH, Tsai CH, Tsai FJ. Vascular endothelial growth factor gene-460 $\mathrm{C} / \mathrm{T}$ polymorphism is a biomarker for oral cancer. Oral Oncol 2005; 41: 497-502.

22. Yapijakis C, Vairaktaris E, Vassiliou S, Vylliotis A, Nkenke E, Nixon AM, et al. The low VEGF production allele of the $+936 \mathrm{C} / \mathrm{T}$ polymorphism is strongly associated with increased risk for oral cancer. J Cancer Res Clin Oncol 2007; 133: 787-791.

23. Vairaktaris E, Serefoglou Z, Avgoustidis D, Yapijakis C, Critselis E, Vylliotis A, et al. Gene polymorphisms related to angiogenesis, inflammation and thrombosis that influence 
risk for oral cancer. Oral Oncol 2009; 45: 247-253.

24. Cheng CY, Chang CS, Liu CJ, Kao SY. Vascular endothelial growth factor $936 \mathrm{C} / \mathrm{T}$ polymorphism is associated with vascular invasion in oral squamous cell carcinoma. Oral Surg Oral Med Oral Pathol Oral Radiol Endod 2008; 106: 79-84.

25. Nasr HB, Chahed K, Bouaouina N, Chouchane L. Functional vascular endothelial growth factor $-2578 \mathrm{C} / \mathrm{A}$ polymorphism in relation to nasopharyngeal carcinoma risk and tumor progression. Clin Chim Acta 2008; 395: 124-129.

26. Unal ZN, Unal M, Bagdatoglu OT, Polat G, Atik U. Genetic polymorphism of VEGF-1154 (A/G) in laryngeal squamous cell carcinoma. Arch Med Res 2008; 39: 209-211.

27. Sobin $\mathrm{LH}$, Wittelind $\mathrm{CH}$. International union against cancer: TNM classification of malignant tumours. 6th edn. New York: Wiley; 2002.

28. Miller SA, Dykes DD, Polesky HF. A simple salting out procedure for extracting DNA from human nucleated cells. Nucleic Acids Res 1988; 16: 1215.

29. Argiris A, Karamouzis MV, Raben D, Ferris RL. Head and neck cancer. Lancet 2008; 371: 1695-1709.

30. Goldstein DP, Irish JC. Head and neck squamous cell carcinoma in the young patient. Curr Opin Otolaryngol Head Neck Surg 2005; 13: 207-211.

31. Brogan IJ, Khan N, Isaac K, Hutchinson JA, Pravica V, Hutchinson IV. Novel polymorphisms in the promoter and 5' UTR regions of the human vascular endothelial growth factor gene. Hum Immunol 1999; 60: 1245-1249.

32. Moriyama M, Kumagai S, Kawashiri S, Kojima K, Kakihara
K, Yamamoto E. Immunohistochemical study of tumour angiogenesis in oral squamous cell carcinoma. Oral Oncol 1997; 33: 369-374.

33. Wong YK, Liu CJ, Kwan PC, Chao SY. Microvascular density and vascular endothelial growth factor immunoreactivity as predictors of regional lymph node metastasis from betelassociated oral squamous cell carcinoma. J Oral Maxillofac Surg 2003; 61: 1257-1262.

34. Shang ZJ, Li JR. Expression of endothelial nitric oxide synthase and vascular endothelial growth factor in oral squamous cell carcinoma: its correlation with angiogenesis and disease progression. J Oral Pathol Med 2005; 34: 134139.

35. Bates DO, Cui TG, Doughty JM, Winkler M, Sugiono M, Shields JD, et al. VEGF165b, an inhibitory splice variant of vascular endothelial growth factor, is down-regulated in renal cell carcinoma. Cancer Res 2002; 62: 4123-4131.

36. Schneider BP, Miller KD. Angiogenesis of breast cancer. $J$ Clin Oncol 2005; 23: 1782-1790.

37. Ferroni P, Spila A, Martini F, D'Alessandro R, Mariotti S, Del Monte G, et al. Prognostic value of vascular endothelial growth factor tumor tissue content of colorectal cancer. Oncology 2005; 69: 145-153.

38. Uehara M, Sano K, Ikeda H, Sekine J, Irie A, Yokota T, et al. Expression of vascular endothelial growth factor and prognosis of oral squamous cell carcinoma. Oral Oncol 2004; 40: 321-325. 